\title{
PENGARUH ADANYA MATERIAL BERPORI TERHADAP KARAKTERISTIK KONSOLIDASI TANAH LEMPUNG LUNAK LAHAN BASAH
}

\author{
${ }^{1)}$ Rusdiansyah \\ ${ }^{1)}$ Teknik Sipil Universitas Lambung Mangkurat Banjarbaru \\ E-mail : rusdinat@yahoo.com
}

\begin{abstract}
ABSTRAK
Salah satu cara untuk mempercepat aliran air maupun laju konsolidasi tanah lempung lunak lahan basah yaitu dengan menambahkan material porous didalam tanah maupun menggunakan drainasi vertical. Selama ini telah berkembang teknologi percepatan konsolidasi dengan vertical drain berbahan geosintetis. Selain berbahan geosintetis, bahan lainnya untuk material vertical drain masih terus dikembangkan untuk mencari keandalan yang ekonomis. Adapun yang menjadi permasalahan dalam penelitian ini adalah bagaimana derajat konsolidasi yang dihasilkan dari hasil pengujian konsolidasi tanah lempung lunak lahan basah yang ditambahkan adanya material berpori (berbahan pasir, sekam padi, dan arang kayu). Selain itu juga bagaimana pengaruh drainase (material berpori) radial, $\mathrm{n}$ (perbandingan diameter benda uji dan diameter drainase (material berpori)dari masingmasing material berpori.Dalam penelitian ini dilakukan uji konsolidasi dengan benda uji menggunakan tanah lempung lunak lahan basah. Pada bagian tengah benda uji diberi lubang berdiameter $0,75 \mathrm{~cm}, 1 \mathrm{~cm}$, dan $1,5 \mathrm{~cm}$, kemudian ditambahkan material berpori berbahan pengisi berupa pasir, sekam padi, dan arang. Dari ketiga material berpori tersebut, selanjutnya akan dibandingkan sesamanya terkait kinerja material berpori sebagai sistem drainase (material berpori) didalam tanah. Hasil penelitian menunjukkan bahwa material sekam padi, pasir, dan arang dapat digunakan sebagai bahan drainase (material berpori) untuk tanah yang berkonsolidasi karena mampu meningkatkan nilai derajat konsolidasi (U\%). Apabila ditinjau pada satu satuan waktu maka untuk jenis material drainase (material berpori)) berbahan sekam dapat menghasilkan derajat konsolidasi yang lebih besar dibandingkan material drainase (material berpori) berbahan pasir maupun arang.Material drainase (material berpori) berbahan sekam dapat menghasilkan nilai koefisien konsolidasi $(\mathrm{Cv})$, nilai koefisien permeabilitas $(\mathrm{k})$, dan nilai koefisien perubahan volume (mv) yang lebih besar dibandingkan dengan material drainase (material berpori) berbahan pasir dan arang.Nilai koefisien konsolidasi $(\mathrm{Cv})$ semakin meningkat seiring dengan peningkatan nilai rasio diameter (n) hingga mencapai rasio diameter yang optimum (nopt), selanjutnya sesudah nilai rasio diameter optimum tercapai maka koefisien konsolidasi akan mengalami penurunan. Rasio diameter optimum pada tanah lempung lunak yang berkonsolidasi didapat pada nilai 6(enam).
\end{abstract}

Kata kunci : Konsolidasi tanah, drainase (material berpori) vertical,derajat konsolidasi,koefisien permeabilitas, koefisien konsolidasi dan tanah lempung lunak lahan basah.

\begin{abstract}
One way to accelerate water flow and the rate of consolidation of wetland soft clay soil is by adding porous material in the soil and using vertical drainage. So far there has been a development of consolidation acceleration technology with a vertical drain made from geosynthetics. Apart from geosynthetics, other materials for vertical drain material are still being developed to find
\end{abstract}


economical reliability. The problem in this research is how the degree of consolidation resulting from the consolidation test of wetland soft clay soil is added by the presence of porous material (made from sand, rice husk, and wood charcoal). In addition, also the effect of radial drainage (porous material), $n$ (comparison of the diameter of the specimen and drainage diameter (porous material) of each porous material. In this study a consolidation test was carried out with specimens using soft soil wetlands. the center of the specimen was given a hole with a diameter of $0.75 \mathrm{~cm}$, $1 \mathrm{~cm}$, and $1.5 \mathrm{~cm}$, then added porous material made from fillers in the form of sand, rice husk, and charcoal. porous material) in the soil The results showed that rice husk, sand and charcoal material can be used as drainage material (porous material) for the soil that consolidates because it can increase the value of the consolidation degree (U\%). for the type of drainage material (porous material) made from chaff can produce console degrees idasi which is bigger than drainage material (porous material) made from sand or charcoal. Drainage material (porous material) made from chaff can produce consolidated coefficient values $(C v)$, permeability coefficient value $(k)$, and volume change coefficient value $(m v)$ which is greater than the drainage material (porous material) made from sand and charcoal. The value of the consolidation coefficient $(\mathrm{Cv})$ increases along with the increase in the diameter ratio (n) until it reaches the optimum diameter ratio (nopt), then after the optimum diameter ratio value is reached, the coefficient of consolidation will decrease. The optimum diameter ratio in soft clay that consolidates is obtained at a value of 6 (six).

Keywords: Soil consolidation, vertical drainage (porous material), degree of consolidation, permeability coefficient, consolidation coefficient, and wetland soft clay soil.

\section{PENDAHULUAN}

\section{Latar Belakang}

Konsolidasi adalah peristiwa keluarnya air dari pori-pori tanah akibat pembebanan di atas tanah sehingga tanah dapat mengalami penurunan. Karena permeabilitas yang kecil, maka penurunan tersebut berlangsung dalam waktu yang lama sehingga sangat merugikan pada pelaksanaan konstruksi.Umumnya tanah lempung lunak lahan basah selalu memiliki laju konsolidasi yang rendah karena karakteristik permeabilitasnya juga rendah. Dalam teori, besar penurunan konsolidasi akhir adalah sama, hanya laju penurunannya yang berbeda-beda. Selama ini laju konsolidasi primer dapat dinaikkan dengan menggunakan drainase (material berpori) vertikal (vertical drain) yang dapat memperpendek lintasan pengaliran air didalam tanah lempung sesudah proses drainase (material berpori) radial berlangsung.

Adanya vertical drain akan mempercepat proses konsolidasi melalui atau memperpendek jalur aliran air horizontal (drainase (material berpori) radial) sehingga selanjutnya dialirkan melalui material vertical drain. Dengan adanya vertical drain maka air didalam tanah bermigrasi kearah horizontal (proses drainase (material berpori) radial) menuju jalur vertical drain yang selanjutnya keluar menuju ke permukaan tanah (Mofiz, 1989).

Salah satu cara untuk mempercepat aliran air/laju konsolidasi tanah lempung lunak lahan basah yaitu dengan menggunakan drainasi vertical. Selama ini telah berkembang teknologi percepatan konsolidasi dengan vertical drain berbahan geosintetis. Selain berbahan geosintetis, bahan lainnya untuk material vertical drain masih terus dikembangkan untuk mencari keandalan yang lebih. $G$ Sumiyati (2015) telah melakukan penelitian mengenai material vertical drain berbahan ijuk dan plastik (dari sampah botol plastik dipotong kecil-kecil). Dalam hasil penelitiannya menunjukkan 
bahwa vertical drain berbahan plastik (dari sampah botol plastik dipotong kecil-kecil) menghasilkan derajat konsolidasi tertinggi dibandingkan vertical drain berbahan Pasir dan Ijuk.

Robinson dan Shilpa (2008) telah menyelidiki pengaruh drainase (material berpori) radial (material drainase (material berpori) vertical drain dari pasir) terhadap lempung bercampur pasir yang terkonsolidasi pada regangan yang sama. Dalam hasil penelitiannya disebutkan bahwa kondisi akhir tanah setelah proses konsolidasi adalah tidak seragam, dimana kadar air tertinggi masih terdapat diluar zona pengaruh vertical drain. Sedangkan kadar air rendah terdapat di area yang berdekatan dengan lubang vertical drain.

Material vertical drain berbahan serabut kelapa dan Ijuk telah diteliti oleh Abadi (2004). Hasil penelitiannya menunjukkan bahwa koefisien konsolidasi arah vertical rata-rata meningkat $1,7 \mathrm{x}$ lipat (untuk vertical drain berbahan serabut kelapa) dan 5,2x lipat (untuk vertical drain berbahan Ijuk) dibandingkan dengan tanpa drainase (material berpori) vertikal

\section{Permasalahan}

Dalam penelitian ini dilakukan percobaan drainase (material berpori) vertical dengan bahan berporidengan pengisi berupa pasir, sekam padi, dan arang. Penelitian ini dilakukan untuk mengetahui kemampuan drainase (material berpori) vertical melalui proses drainase (material berpori) radial dengan bahan pengisi pasir, sekam padi, dan arang terhadap kecepatan penurunan tanah lempung lunak lahan basah. Dari ketiga material akan dibandingkan sesamanya. Alasan menggunakan sekam padi dan Arang Kayu adalah karena bahan tersebut merupakan material limbah yang mudah didapat, harganya murah, dan belum dimanfaatkan sebagai bahan alternatif untuk drainase (material berpori) vertical yang dapat mempercepat penurunan tanah lempung lunak lahan basah. Sedangkan material pasir adalah sebagai pembanding lainnya. Sehingga dengan menggunakan bahan-bahan tersebut diharapkan dapat diperoleh informasi mengenai perilaku konsolidasi melalui analisis terhadap drainase (material berpori) radial yang merupakan bagian proses awal dari drainase (material berpori) vertical. Selain itu mengingat bahwa ada kondisi dimana kadang-kadang suatu metode yang bernilai ekonomis dapat digunakan untuk mempercepat proses konsolidasi, diantaranya dengan memanfaatkan bahan-bahan yang dipilih dalam penelitian ini.

\section{Rumusan Penelitian}

Bangunan tangki adalah bangunan vital yang harus didukung oleh pondasi yang kokoh dan stabil. Jika terjadi kegagalan pada pondasi tangki akan mengalami kerusakan dan tangki tidak layak dipergunakan. Dengan hal tersebut maka dirumuskan masalah penelitian dengan pertanyaan penelitian sebagai berikut :

1. Bagaimana gambaran rinsip dasar penggunaan alat instrumen kontrol pile drive analyzer pada pengujian daya dukung tiang pancang

2. Bagaimana gambaran metode pelaksanaan pengujian daya dukung taing pancang dengan alat instrumen kontrol pile drive analyzer.

\section{Tujuan Penelitian}

Adapun tujuan dalam penelitian ini adalah untuk :

1. Mengetahui perbandingan nilai derajat konsolidasi tanah lempung lunak lahan basah tanpa adanya tambahan material berpori.

2. Mengetahui perbandingan nilai derajat konsolidasi tanah lempung lunak lahan basah yang diberitambahan material berporiberbahan pasir, sekam padi, dan arang kayu. 
3. Mengetahui pengaruh adanya drainase (material berpori) radial dari vertical drain berbahan (pasir, sekam padi, dan arang kayu) terhadap perilaku konsolidasi tanah lempung lunak lahan basah.

\section{Rumusan Penelitian}

Rumusan penelitian ini dirumuskan dengan pertanyaan sebagai berikut :

1. Bagaimana gambaranperbandingan nilai derajat konsolidasi tanah lempung lunak lahan basah tanpa adanya tambahan material berpori?

2. Bagaimana gambaran perbandingan nilai derajat konsolidasi tanah lempung lunak lahan basah yang diberi tambahan material berpori berbahan pasir, sekam padi, dan arang kayu ?

3. Bagaimana mengetahui pengaruh adanya drainase (material berpori) radial dari vertical drain berbahan (pasir, sekam padi, dan arang kayu) terhadap perilaku konsolidasi tanah lempung lunak lahan basah?

\section{METODE PENELITIAN}

\section{Pengambilan Sampel, Bahan dan Alat}

Proses pengambilan sampel pada penelitian ini dilakukan dengan cara pengambilan sampel tanah tak terganggu (undisturbed) menggunakan handboring di lapangan.Bahan yang digunakan dalam penelitian ini adalah berupa sampel tanah lempung lunak yang diambil di Kecamatan Sungai Tabuk Kabupaten Banjar Provinsi Kalimantan Selatan. Sedangkan material drainase (material berpori) seperti pasir diperoleh berasal dari Kecamatan Cempaka. Untuk material sekam padi diperoleh dari area persawahan Sungai Tabuk, Kabupaten Banjar.Material drainase (material berpori) lainnya adalah Arang. Arang adalah merupakan limbah arang kayu yang bersumber dari di Desa Sungai Pinang Kecamatan Daha Selatan Kabupaten Hulu Sungai Selatan, Provinsi Kalimantan Selatan.Arang yang digunakan dalam penelitian ini adalah arang kayu yang merupakan bahan untuk pembakaran besi yang sudah tidak terpakai lagi dan kemudian dihaluskan (lolos saringan no. 40) menjadi berukuran seperti filler (serbuk). Dalam Gambar 1 ditunjukkan alur penelitian untuk mencapai tujuan dalam penelitian ini. 


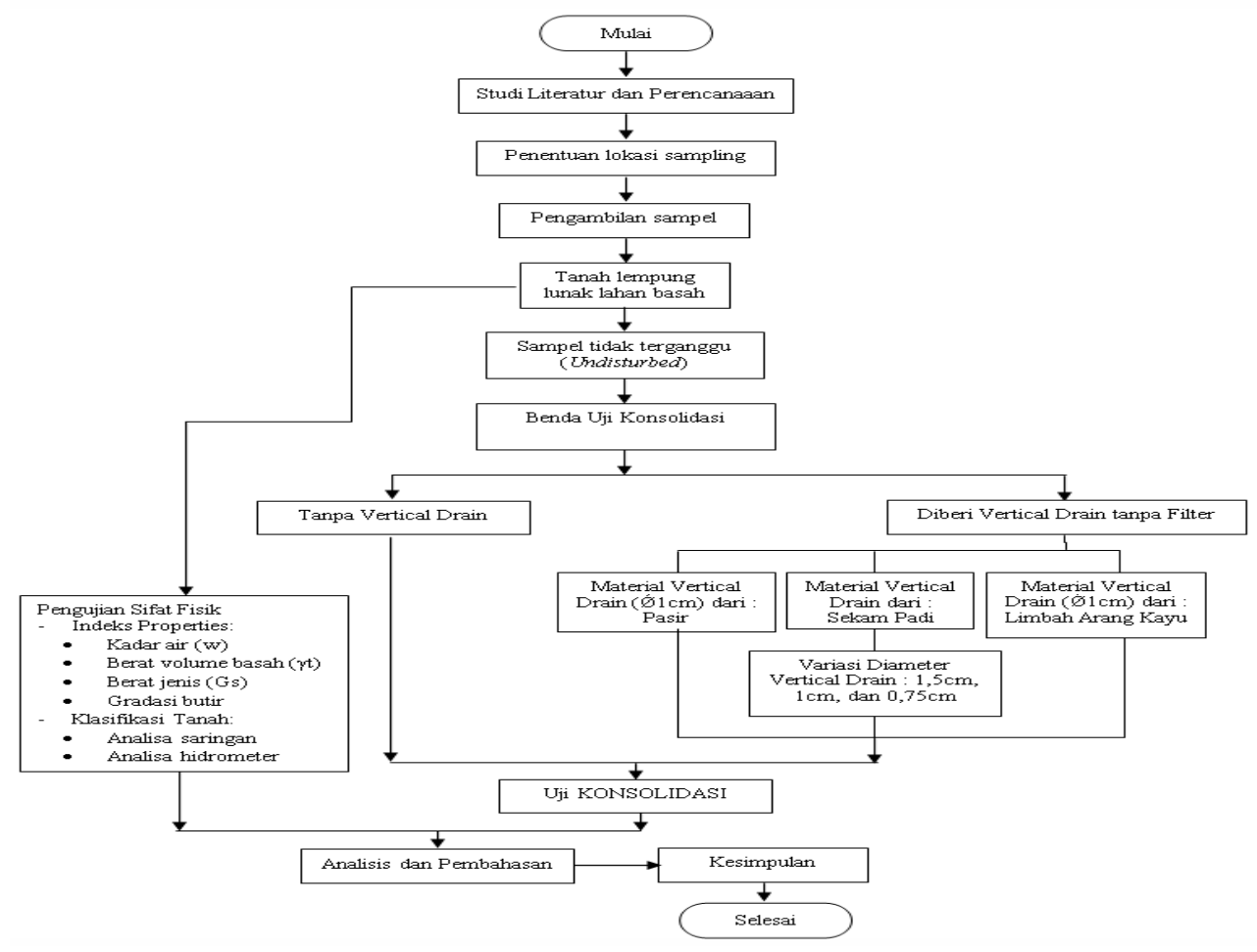

Gambar 1. Flowchart Penelitian

\section{HASIL DAN PEMBAHASAN}

\section{Karakteristik Tanah Lempung Lunak}

Karakteristik tanah yang digunakan sebagai benda uji dalam penelitian ini adalah tergolong tanah lempung lunak. Hal ini ditunjang dari beberapa parameter sifat fisik dan mekanis tanah tersebut yang ditunjukkan dalam Tabel 1 dan Gambar 2.Dalam Tabel 1 ditunjukkan antara lain bahwa pada tanah yang digunakan sebagai benda uji memiliki nilai Indeks Plastis yang memenuhi kategori tanah lempung. Selain itu juga berdasarkan Gambar 1 ditunjukkan bahwa tanah yang digunakan sebagai benda uji adalah tergolong tanah $\mathrm{OH}$ menurut USCS. Hal ini juga didukung berdasarkan hasil visualisasi di lapangan.

Tabel 1. Karakteristik Tanah Lempung Undisturbed

\begin{tabular}{|l|c|}
\hline \multicolumn{1}{|c|}{ Sifat Fisik dan Mekanis } & Besaran \\
\hline Water content (\%) & 63.14 \\
\hline Volumetric weight (gr/cm3) & 1.468 \\
\hline Liquid limit (\%) & 63.19 \\
\hline Plastic limit (\%) & 38.44 \\
\hline Plasticity Index (\%) & 24.76 \\
\hline Vane shear test $(\mathrm{Su})(\mathrm{kN} / \mathrm{m} 2)$ & 16 \\
\hline $\mathrm{Cc}$ & 0.616 \\
\hline $\mathrm{Cs}$ & 0.069 \\
\hline
\end{tabular}

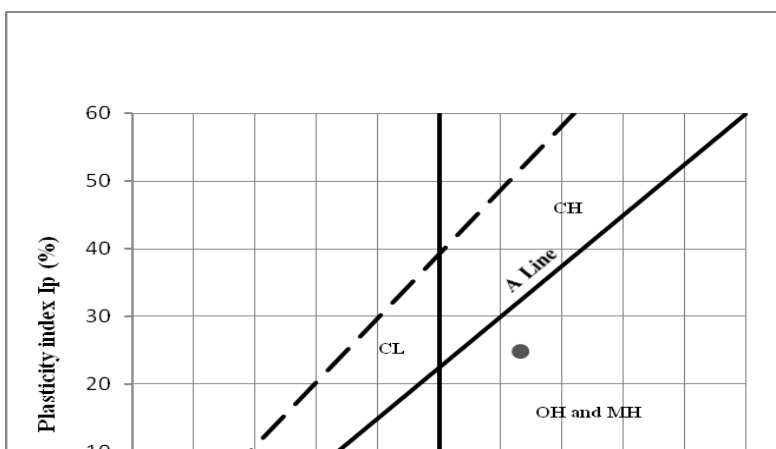




\section{Hubungan Material Drainase (material berpori) dan Derajat Konsolidasi}

Pengujian konsolidasi dengan berbagai tambahan macam material drainase (material berpori) radial telah dilakukan di laboratorium dengan menggunakan alat uji konsolidasi di laboratorium. Material drainase (material berpori) radial yang digunakan berupa pasir, sekam padi, dan arang. Dalam Gambar 3 ditunjukkan hubungan derajat konsolidasi dan waktu konsolidasi untuk masing-masing jenis material drainase (material berpori)pada benda uji. Berdasarkan gambar tersebut bahwa secara umum derajat konsosidasi semakin meningkat seiring dengan pertambahan waktu terjadinya konsolidasi. Selain itu bahwa adanya material drainase (material berpori) didalam tanah maka dapat mempercepat waktu konsolidasi yang dihasilkan. Material sekam padi, pasir, dan arang dapat digunakan sebagai bahan drainase (material berpori)pada tanah yang berkonsolidasi karena mampu meningkatkan nilai derajat konsolidasi (U,\%).

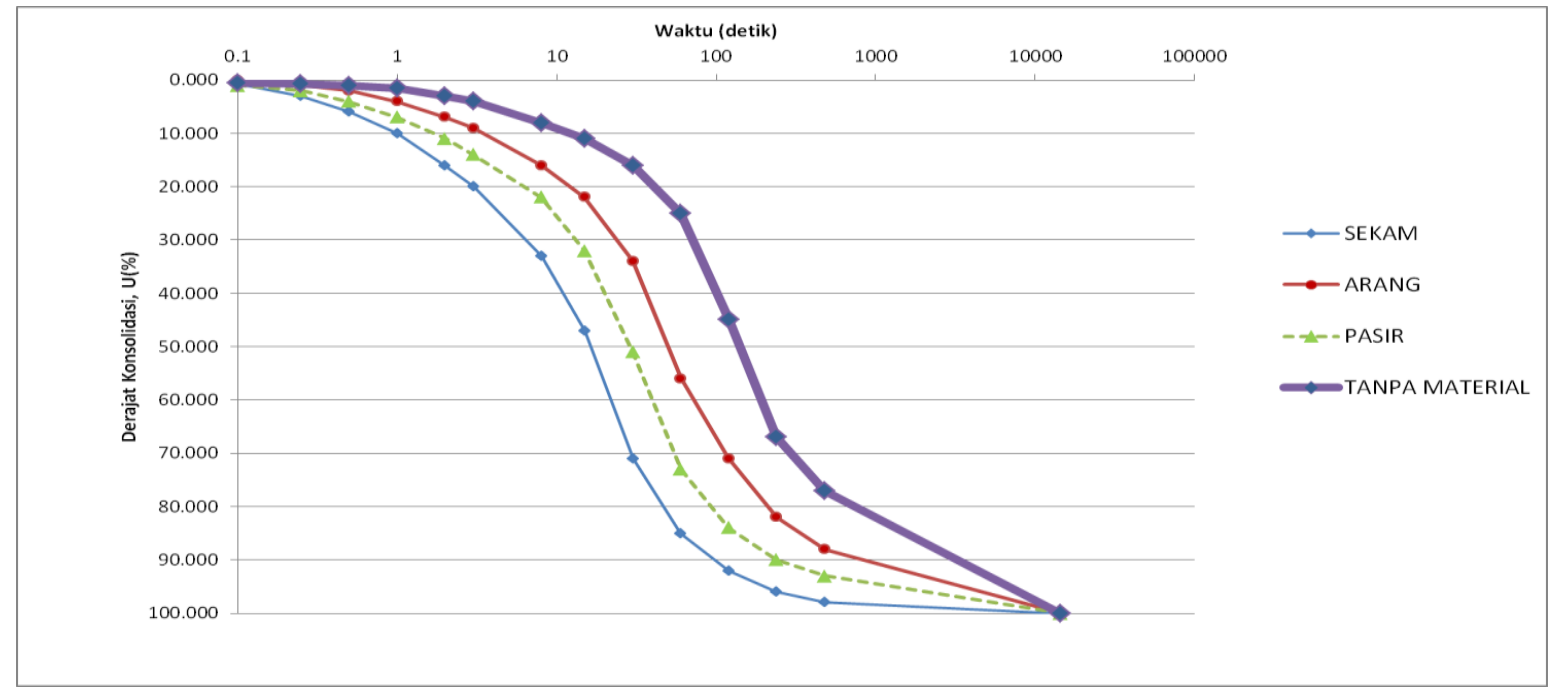

Gambar 3. Kurva Hubungan Derajat Konsolidasi dan Waktu

Untuk Masing-masing Jenis Material Drainase (material berpori)

Pada Gambar 3 juga ditunjukkan bahwa secara berurutan, jenis material drainase (material berpori) arang, pasir dan sekam adalah mempersingkat waktu konsolidasi, dimana apabila ditinjau pada satu satuan waktu maka untuk jenis material drainase (material berpori) berbahan sekam dapat menghasilkan derajat konsolidasi yang lebih besar dibandingkan material drainase (material berpori) berbahan pasir dan arang. Demikian juga untuk material drainase (material berpori) berbahan pasir dapat menghasilkan waktu konsolidasi yang lebih singkat dibandingkan dengan material drainase (material berpori) berbahan arang. 


\section{Hubungan Material Drainase (material berpori) dan Koefisien Konsolidasi}

Hubungan material drainase (material berpori) radial dan koefisien konsolidasi ( $\mathrm{Cv}$ ) dapat dijelaskan melalui kurva yang ditunjukkan dalam Gambar 4. Pada gambar tersebut dapat dijelaskan secara umum bahwa tanah lempung yang sedang berkonsolidasi akan memiliki nilai koefisien konsolidasi $(\mathrm{Cv})$ lebih rendah dibandingkan dengan tanah lempung pada kondisi telah diberi material drainase (material berpori) vertical. Material sekam padi, pasir, dan arang dapat digunakan sebagai bahan drainase (material berpori) untuk tanah yang berkonsolidasi karena mampu meningkatkan nilai koefisien konsolidasi $(\mathrm{Cv})$.

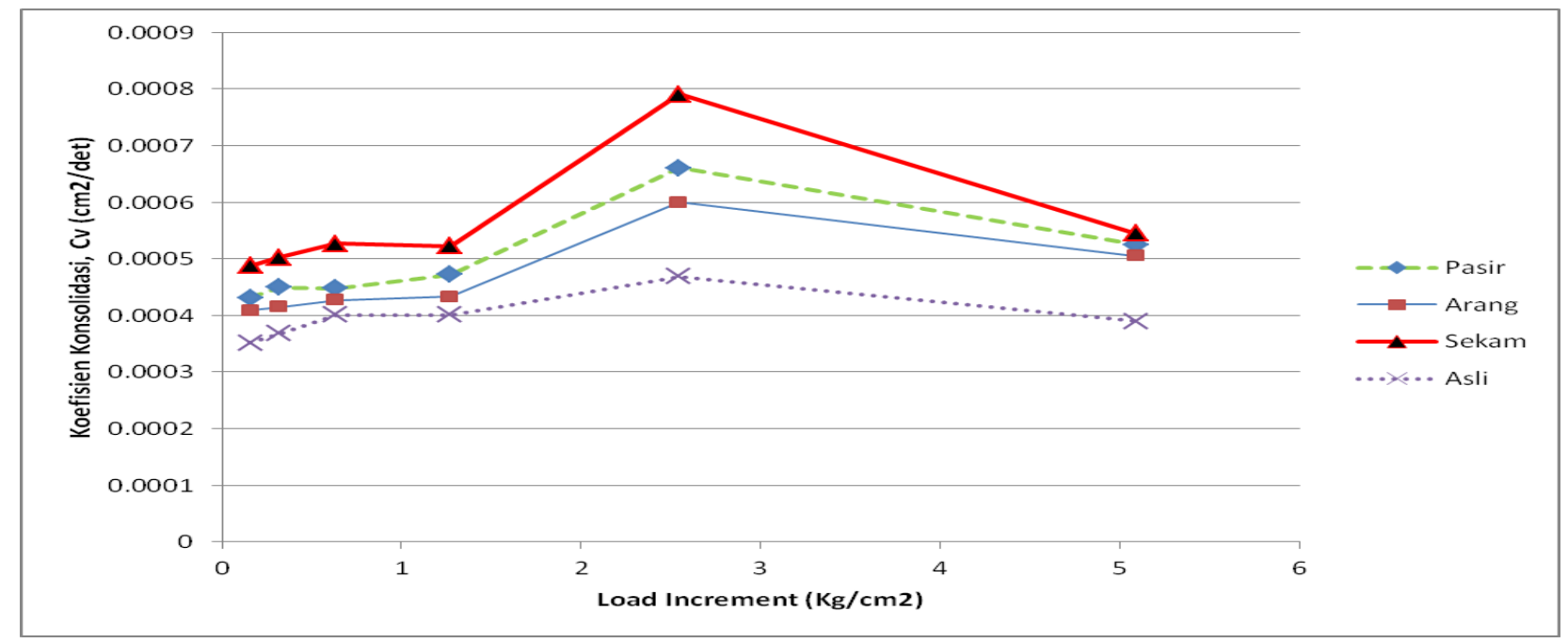

Gambar 4. Kurva Hubungan Koefisien Konsolidasi dan Kenaikan Beban untuk Masing-masing Jenis Material Drainase (material berpori)

Pada Gambar 4 ditunjukkan bahwa tanah lempung yang berkonsolidasi pada kondisi diberi tambahan material drainase (material berpori) berbahan sekam dapat menghasilkan nilai koefisien konsolidasi $(\mathrm{Cv})$ yang lebih besar dibandingkan dengan material drainase (material berpori) berbahan pasir dan arang.

\section{Hubungan Material Drainase (material berpori) dan Diameter terhadap dan Koefisien Perubahan Volume (mv)}

Pengaruh jenis material drainase (material berpori) terhadap koefisien perubahan volume (mv) dari tanah lempung yang berkonsolidasi ditunjukkan pada Gambar 5. Sedangkan pengaruh diameter drainase (material berpori) terhadap terhadap koefisien perubahan volume (mv) dari tanah lempung yang berkonsolidasi ditunjukkan pada Gambar 6.

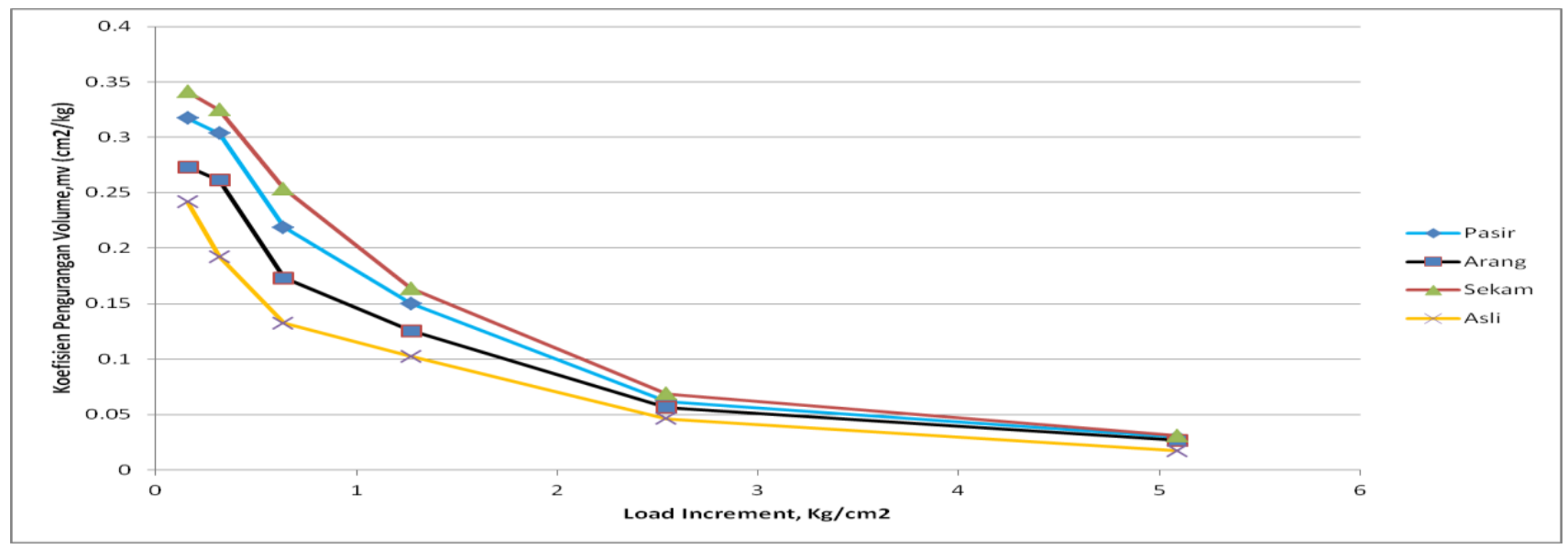


Gambar 5. Kurva Hubungan Perubahan Volume (mv) dan Kenaikan Beban untuk Masing-masing Jenis Material Drainase (material berpori)

Berdasarkan Gambar 5 dapat dijelaskan bahwa adanya material drainase (material berpori) didalam tanah lempung yang sedang berkonsolidasi ternyata dapat meningkatkan nilai koefisien perubahan volume (mv) dibandingkan tanpa adanya tambahan material drainase (material berpori) didalam tanah lempung tersebut. Nilai koefisien perubahan volume (mv) untuk material drainase (material berpori) berbahan sekam memiliki nilai yang lebih tinggi dibandingkan dengan material berbahan pasir dan arang.

Dalam Gambar 6 dijelaskan bahwa semakin besar diameter drainase (material berpori) didalam tanah lempung yang sedang berkonsolidasi maka semakin meningkat pula nilai koefisien perubahan volume (mv) yang dihasilkan. Selain itu bahwa semakin besar kenaikan beban yang diterapkan maka nilai koefisien perubahan volume (mv) cenderung semakin kecil.

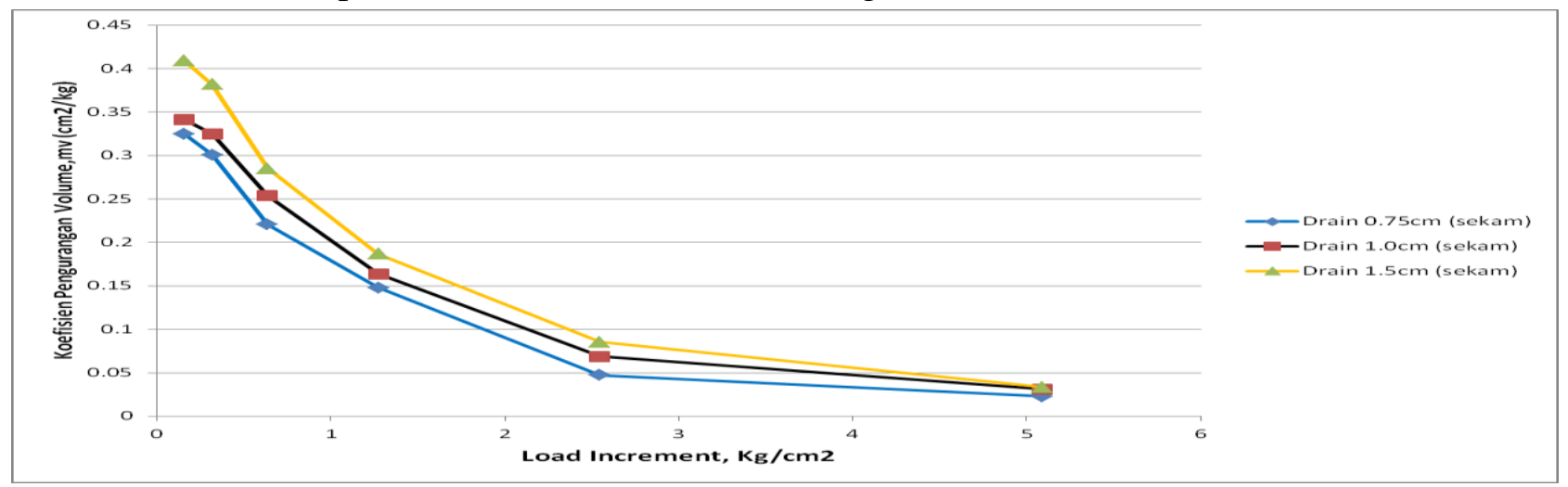

Gambar 6. Kurva Hubungan Perubahan Volume (mv) dan Kenaikan Beban untuk Jenis Material Drainase (material berpori) dari bahan Sekam Hubungan Material Drainase (material berpori) dan Diameter terhadap dan Koefisien
Permeabilitas (k)

Nilai koefisien permeabilitas tanah lempung lunak berkonsolidasi dapat dipengaruhi oleh adanya material drainase (material berpori) didalamnya. Hal ini seperti yang ditunjukkan didalam Gambar 7. Berdasarkan gambar tersebut dapat dijelaskan bahwa material drainase (material berpori) berbahan sekam menghasilkan nilai koefisien permeabilitas yang lebih tinggi dibandingkan dengan material drainase (material berpori) dari pasir dan arang. Hal ini menunjukkan bahwa material sekam adalah lebih porous dibandingkan dengan pasir dan arang.

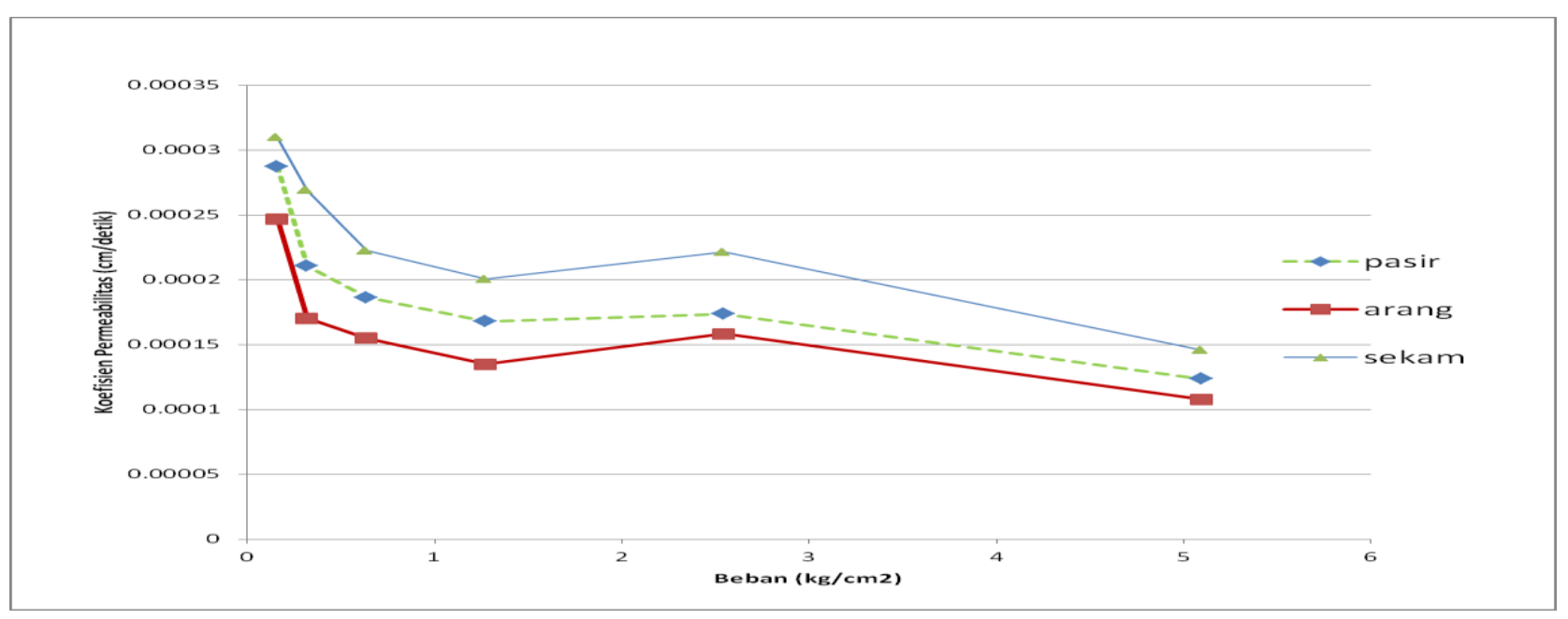

Gambar 7. Kurva Hubungan Koefisien Permeabilias (k) dan Kenaikan Beban konsolidasi 


\section{Pengaruh Rasio Diameter Ekivalen dan diameter Drainase (material berpori) terhadap Koefisien Konsolidasi (Cv)}

Dalam rangka ingin mengetahui pengaruh diameter drainase (material berpori) terhadap kecepatan konsolidasi atau koefisien konsolidasi maka dilakukan variasi diameter drainase (material berpori) pada masing-masing tanah lempung lunak yang berkonsolidasi. Dalam Gambar 8 ditunjukkan pengaruh rasio diameter terhadap nilai koefisien konsolidasi $(\mathrm{Cv})$. Rasio diameter merupakan hubungan perbandingan antara diameter ekivalen tanah lempung dan diameter drainase (material berpori).

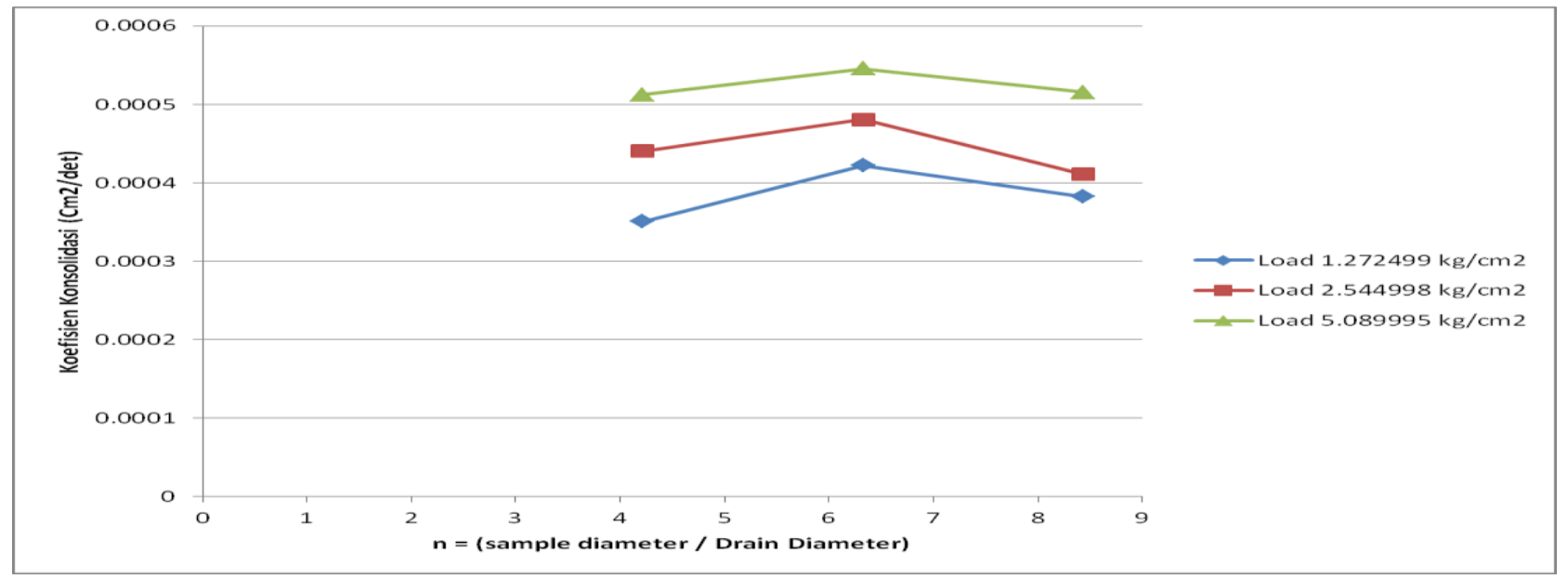

Gambar 8. Kurva Hubungan Koefisien Konsolidasi (Cv) dan Rasio Diameter

Berdasarkan Gambar 8 dapat dijelaskan bahwa nilai koefisien konsolidasi $(\mathrm{Cv})$ semakin meningkat seiring dengan peningkatan nilai rasio diameter (n) hingga mencapai rasio diameter yang optimum (nopt), selanjutnya sesudah nilai rasio diameter optimum tercapai maka koefisien konsolidasi akan mengalami penurunan. Rasio diameter optimum pada tanah lempung lunak yang berkonsolidasi didapat pada besaran sama dengan 6 (enam).

\section{Perilaku konsolidasi tanah akibat adanya material drainase (material berpori) vertikal}

Berdasarkan hasil pengujian konsolidasi menunjukkan bahwa adanya material drainase (material berpori) didalam tanah dapat mempengaruhi perilaku konsolidasi tanah tersebut, dimana garis gradient Cc untuk tanah dengan tambahan material drainase (material berpori) adalah lebih rendah dibandingkan dengan tanah lempung tanpa material drainase (material berpori). Hal ini seperti yang telah ditunjukkan didalam Gambar 9.

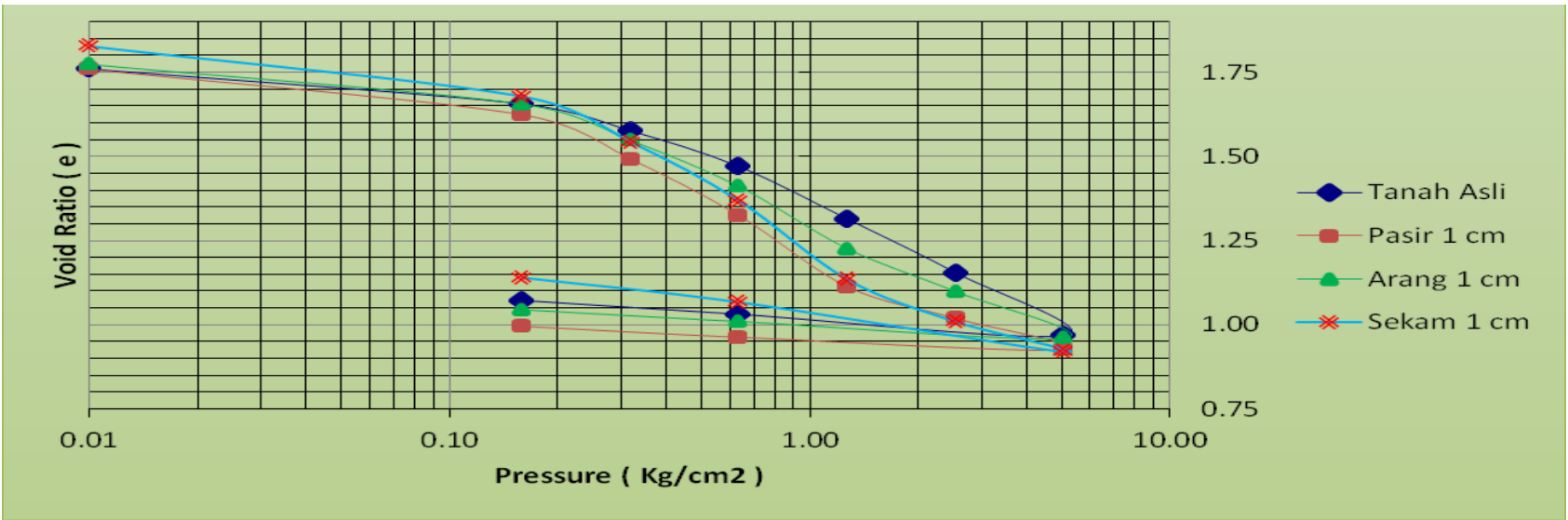


Gambar 9. Kurva Hubungan Tekanan dan Angka Pori akibat material drainase (material berpori)

Dalam Gambar 9 ditunjukkan bahwa secara umum adanya material drainase (material berpori) dapat memperkecil angka pori apabila ditinjau pada nilai tekanan konsolidasi yang sama. Selain itu juga ditunjukkan bahwa perilaku konsolidasi untuk tanah lempung yang ditambahkan dengan material drainase (material berpori) berbahan pasir menghasilkan garis gradient Cc (indeks pemampatan) yang lebih rendah dibandingkan dengan material drainase (material berpori) lainnya (sekam dan arang). Hal ini karena kekuatan pasir dalam menerima tekanan adalah lebih tinggi dibandingkan dengan material lainnyya (sekam dan arang).

\section{Kesimpulan}

\section{PENUTUP}

Berdasarkan hasil analisa yang telah diuraikan maka dapat disimpulkan sebagai berikut :

1. Material sekam padi, pasir, dan arang dapat digunakan sebagai bahan drainase (material berpori) untuk tanah yang berkonsolidasi karena mampu meningkatkan nilai derajat konsolidasi $(\mathrm{U}, \%)$.

2. Apabila ditinjau pada satu satuan waktu maka untuk jenis material drainase (material berpori) berbahan sekam dapat menghasilkan derajat konsolidasi yang lebih besar dibandingkan material drainase (material berpori) berbahan pasir dan arang.

3. Material drainase (material berpori) berbahan sekam dapat menghasilkan nilai koefisien konsolidasi $(\mathrm{Cv})$, nilai koefisien permeabilitas $(\mathrm{k})$, dan nilai koefisien perubahan volume (mv) yang lebih besar dibandingkan dengan material drainase (material berpori) berbahan pasir dan arang.

4. Nilai koefisien konsolidasi $(\mathrm{Cv})$ semakin meningkat seiring dengan peningkatan nilai rasio diameter (n) hingga mencapai rasio diameter yang optimum (nopt), selanjutnya sesudah nilai rasio diameter optimum tercapai maka koefisien konsolidasi akan mengalami penurunan. Rasio diameter optimum pada tanah lempung lunak yang berkonsolidasi didapat pada besaran sama dengan 6(enam).

5. Semakin besar diameter drainase (material berpori) didalam tanah lempung yang sedang berkonsolidasi maka semakin meningkat pula nilai koefisien perubahan volume (mv) yang dihasilkan.

\section{Saran}

1. Untuk penelitian lebih lanjut dapat dikembangkan pengaruh material berpori berbahan limbah pecahan bahan bangunan (berukuran kecil) agar nilai ekonomis dapat diperoleh lebih maksimal.

2. Dalam penelitian serupa yang akan datang sebaiknya menggunakan benda uji yang berukuran yang lebih besar agar drainase radial lebih mendekati kondisi lapangan.

\section{Ucapan Terimakasih}

Ucapan terima kasih disampaikan kepada Program Studi Magister Teknik Sipil Fakultas Teknik Universitas Lambung Mangkurat yang telah mendukung danmembantu pembiyaan pelaksanaan penelitian iniuntuk Tahun Anggaran 2017.

\section{DAFTAR PUSTAKA}

Abadi (2004), Uji Laboratorium Pemamfaatan Serabut Kelapa dan Ijuk sebagai bahan Drainase (material berpori) Vertikal tanpa Filter, Media Teknik, No.1 Tahun XXVI, Edisi Februari 2004, ISSN 0216-3012 
Das B.M (1998), Principles of Geotechnical Engineering, PWS. Publishing Company, Boston, Massachusetts.

Eberemu (2011), Consolidation Properties of Compacted Lateritic Soil Treated With Rice Husk Ash, Geomaterials, 1, 70-78. doi:10.4236/9m2011.13011,Published online October 2011, http://www.scirp.org/journal/gm.

G Sumiyati (2015), Percepatan Penurunan Tanah dengan Metode Elektrokinetik, Bahan Ijuk, dan Sampah Plastik Sebagai Drainase (material berpori) Vertikal, Prosiding Konferensi Nasional Teknik SIpil 9 (KoNTeks9), Komda VI BMPTTSSI, Makassar, 7-8 Oktober 2015.

Indraratna, et al (2003), Modelling of Preabricated Vertical Drains in Soft Clay and Evaluation of Their Effectiveness in Practice, Journal of Ground Improvement, 7(3), 2003, PP 127-138, University of Wollongong Research Online.

Indraratna (2005), Radial Consolidation of Clay Using Compressibility Indice and Varying Horizontal Permeability, Canadian Geotechnical Journal, 42, 2005, PP 1330-1341

Mofiz (1989), Effect of Drains on Shear Strength and Consolidation Behaviour of Clay, Thesis, University of Engineering and Tech nology, Dhaka, Bangladesh.

Robinson and Shilpa (2008), Equal Strain Consolidation of Clays Under Radial Drainage, Indian Geotechnical Journal, 38(2), 2008, PP.204-220 